\title{
Growth and production kinetics of antimicrobial compound from Streptomyces albidoflavus 321.2
}

\author{
Raj Narayan Roy ${ }^{1}$ and Sukanta Kumar Sen ${ }^{2 *}$ \\ ${ }^{1}$ Dr. B N Dutta Smriti Mahavidyalaya, Hatgobindopur, Burdwan- 713407, West Bengal, India. \\ ${ }^{2}$ School of Life Sciences, Department of Botany Visva-Bharati, Santiniketan-731235, India.
}

Accepted 28 April, 2011

\begin{abstract}
In this study, an antimicrobial compound was isolated from the fermented broth of Streptomyces albidoflavus 321.2 (MTCC 3662), a new soil isolate. Arginine glycerol salt medium was found best for the production and was maximum after the $6^{\text {th }}$ day of fermentation at $32^{\circ} \mathrm{C}$ using $6 \%(\mathrm{v} / \mathrm{v})$ inoculum at static condition to yield $250 \mu \mathrm{g} / \mathrm{ml}$. The compound exhibited less toxicity against experimental plant and animal systems.
\end{abstract}

Key words: Streptomyces, antimicrobial, fermentation, optimization.

\section{INTRODUCTION}

Indiscriminate use of antimicrobials enhances the probability of microbial resistance. Resistance is also with the use of continuous and developed antimicrobial compounds. Commonly used synthetic chemicals (Sosa and Cventic, 2005; Pepeljnjak et al., 2005; Mohamed et al., 2005) are sharply losing its acceptability mainly due to cause by environmental problems (Wang et al., 1999). Thus, it necessitates searching for new natural antimicrobial compounds to support the medical practitioners and also to the pharmaceutical industries (Mendo et al., 2004). The genus Streptomyces is the largest producer of commercially important antimicrobials. A model suggested that the number of bioactive compounds from Streptomyces would be very close to a lakh and a fraction of which had been unearthed so far (Watve et al., 2001). It further emphasized the need to continue the search programme.

The efficiency of a producer largely depends upon the nutritional and environmental conditions (Ueki et al., 1997). There is no common methodology to ascertain the growth and production ability of microorganisms. It is recommended that by varying the conditions of cultivation, one can stimulate the production ability. Such conditions emphasize to pay special attention to the

*Corresponding author. E-mail: rajnarayanroy@gmail.com. Tel: +91-3463-261686. Fax: +91-3463-261268. selection of suitable medium to enhance the rate of physicochemical reactions to ease production. To ensure good screening practice for antibiotic, it is important to explore new areas from where organisms with potential usefulness can be identified (Umezawa, 1982). Enzymatic potential of Streptomyces albidoflavus has been reported (Bressollier et al., 1999), however, the isolate $S$. albidoflavus 321.2 , showed notable antimicrobial activity. The $\mathrm{pH}$ - and thermo - tolerant, active compound (Roy and Sen, 2006) was identified as dibutylphthalate (DBP), an antimetabolite of proline (Roy et al., 2006). This report describes physical growth kinetics for the optimal production of antimicrobial compound by S. albidoflavus 321.2 (MTCC 3622), a new soil isolate and evaluation of its toxicity.

\section{MATERIALS AND METHODS}

\section{Microorganism used}

The producer organism, S. albidoflavus 321.2 [MTCC 3662], a soil isolate (Roy and Sen, 2002), was maintained in glucose-asparagine agar and test organism Escherichia coli ATCC 25922 in nutrient agar. Organisms were stored at $4^{\circ} \mathrm{C}$.

\section{Media and inoculum}

Several recommended media for streptomycete (mentioned elsewhere) were tested. For inoculum, suspension of $1.2 \times 10^{7}$ 
spores $/ \mathrm{ml}$ of well-sporulated (10 days old) slant was made.

\section{Fermentation condition}

Fermentation was carried out for 7 days at initial $\mathrm{pH}$ of 7.0 and at $30^{\circ} \mathrm{C}$ using $4 \%$ inoculums, if not stated otherwise. Fermentation parameter was optimized by varying one condition and keeping the rest constant.

\section{Growth measurement}

The cell mass was separated from fermented broth by centrifugation (5000 rpm, $15 \mathrm{~min}$ ), washed properly with distilled water and dried at $70^{\circ} \mathrm{C}$ for $16 \mathrm{~h}$. The growth was estimated in terms of dry weight $(\mathrm{mg} / 25 \mathrm{ml})$.

\section{Antimicrobial assay}

After cell separation, clear and faint yellow supernatant was used as crude to test for its antimicrobial activity by agar cup assay method (Higashida et al., 1971). In petridish, glucose-asparagine agar medium was surface seeded with $1 \mathrm{ml}$ of test organism $\left(1.2 \times 10^{6} \mathrm{CFU}\right)$. After solidification, cups $(9 \mathrm{~mm}$, diameter) were made and filled with crude active compound $(0.1 \mathrm{ml})$ and incubated at $30^{\circ} \mathrm{C}$ for $24 \mathrm{~h}$. The inhibition zone diameter was recorded.

\section{Yield}

Yield $(\mu \mathrm{g} / \mathrm{ml})$ was determined using a standard calibration curve of purified sample against the same test organism (E. coli).

\section{Toxicity test}

Both plant and animal toxicity tests were done. To measure the rate of photosynthesis, fresh twig of Hydrilla plant $(\sim 3 \mathrm{~g})$ was used against active compound (50,100, 200,300, 400, and $500 \mu \mathrm{g} / \mathrm{ml})$ with $\mathrm{NaHCO}_{3}$ (trace) as inducer. Keeping it for 30 min, in normal sunlight, the amount of oxygen liberated in each set was recorded from the graduated tube. To test the cell membrane permeability, test was conducted with plant cells. For this purpose, thoroughly washed fresh beet roots were scooped out with cork borer to produce $7 \times 2 \mathrm{~mm}^{3}$ cylinders. After proper washing, the slices $(\sim 4 \mathrm{~g})$ were placed into solution of active compound $(\sim 10 \mathrm{ml}$ of 50,100 , $200,400$, and $500 \mu \mathrm{g} / \mathrm{ml})$ in test tubes. Keeping the set for $6 \mathrm{~h}$ at $30 \pm 2{ }^{\circ} \mathrm{C}$, the leached out pigment was recorded at $520 \mathrm{~nm}$ using spectrophotometer (JASCO, 7800, Japan). Animal toxicity test was performed following the method of Ezaki et al. (1995). Sterile solution of active compound was injected intraperitonially (100 $\mathrm{mg} / \mathrm{Kg}$ body weight) into male mice (Swiss albino strain) having average body weight of $22 \mathrm{~g}$. They were observed for 60 days under standard condition. The optimized parameter of an experiment was considered for designing of subsequent experiments. All the experiments were made in triplicate in all treatments and each test case.

\section{RESULTS AND DISCUSSION}

Cell metabolism depends upon adequate supply of energy, thus, quality of medium. Hence, formulation of medium and designing of growth and production conditions are essential part of successful fermentation experiments, as there is no common recommended medium for fermentation of antimicrobial compound. The production ability of the isolate 321.2 was tested with commonly used media for Streptomyces. It was found that the isolate 321.2 could produce maximally in arginine glycerol salt (AGS) medium, followed by Gause's mineral salt medium and ISP-5 (Table 1). Though soybean meal broth supported growth maximally but considering the yield, AGS medium was selected for further optimization.

Likewise medium suitability, physical parameters also influence the physiological performance of organisms. To any optimization process, the period of fermentation is very crucial. Therefore, to optimize the fermentation period for growth and production, experiment was continued up to 9 days. The results revealed that the growth and production increased with the extended fermentation period which was up to day 6 , thereafter, the yield declined (Figure 1). The lysis of hyphae probably causes the lowering of $\mathrm{pH}$ value, in addition to the accumulation of organic acids that lead to alter the environmental growth condition. Optimum production at $6^{\text {th }}$ day was also reported with Streptomyces sp. (Kojiri et al., 1992). Further, to optimize the temperature, experiment was conducted in a range of 25 to $40^{\circ} \mathrm{C}$. Most favourable growth was found in between 30 to $34^{\circ} \mathrm{C}$. But the highest yield was recorded at $32^{\circ} \mathrm{C}$; above this temperature growth, production was declined, indicating its mesophilic nature (Figure 2). Temperature suitability of streptomycetes was also observed as $32^{\circ} \mathrm{C}$ (Boeck et al., 1985). For the successful fermentation experiment, inoculum size is an important factor. While standardizing the optimum inoculum size for growth and production, 2 to $10 \%(\mathrm{v} / \mathrm{v})$ of inoculum was attempted. An inoculum size of 10 and $6 \%$ were found best for growth and production, respectively (Figure 3). Franco et al. (2000) used 8-10\% vegetative inoculum for Streptomyces Y-86, 36923 and $10 \%$ inoculum was used for $S$. hygroscopicus (Bhattacharyya and Sen, 2002). The $\mathrm{pH}$ of medium is vital for biosynthesis of cell metabolites and their dissociation. The growth and production was found optimum at initial $\mathrm{pH}$ of 7.0 and 6.75, respectively (Figure 4). Neutral pH is most favoured by Streptomycetes (Williams et al., 1971). Likewise, the isolate 321.2 is found to produce optimally at $\mathrm{pH}$ near neutrality (ElGammal, 1986).

Acceptability of a new compound depends much on its toxicity value. Thus, toxicity test is an integral part of the research for antimicrobial compound and commonly subjected to both plant and animal systems. To study the phytotoxicity, the rate of photosynthesis of treated plants revealed that the photosynthetic rate gradually decreased with the increase in concentration of active compound (Figure 5a). However, only $14 \%$ loss of photosynthetic rate was observed at $500 \mu \mathrm{g} / \mathrm{ml}$ concentration. The effect 
Table 1. Suitability of medium for growth and antimicrobial production by isolate 321.2.

\begin{tabular}{|c|c|c|}
\hline Medium & Growth $(\mathrm{mg} / 25 \mathrm{ml})$ & Yield $(\mu \mathrm{g} / \mathrm{ml})$ \\
\hline Glucose-asparagine (Krainsky, 1941) & 040 & - \\
\hline Pridham and Gottlieb (Pridham and Gottlieb, 1948) & 075 & 100 \\
\hline Lindenbein (Lindenbein, 1952) & 060 & 135 \\
\hline Mineral salts (Gause et al., 1958) & 060 & 145 \\
\hline Arginine glycerol salt (El-Nakeeb and Lechevalier, 1963) & 050 & 175 \\
\hline ISP-2 (Pridham et al., 1956) & 080 & - \\
\hline Starch-yeast extract (Agate and Bhat, 1963) & 045 & 125 \\
\hline ISP-5 (Pridham and Lyons, 1961) & 060 & - \\
\hline Sporulating medium (Hobbs et al., 1989) & 100 & 145 \\
\hline Sucrose nitrate (Waksman, 1957) & 125 & - \\
\hline Soybean meal (Tsao et al., 1960) & 150 & 085 \\
\hline Glucose-peptone-yeast extract (Abou-Zeid et al., 1991) & 075 & 050 \\
\hline
\end{tabular}

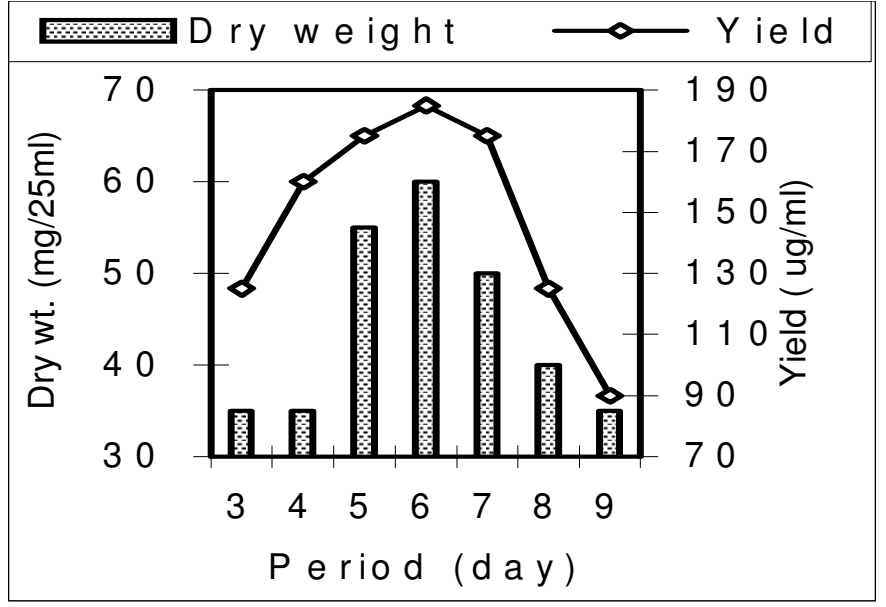

Figure 1. Effect of time period for growth and antimicrobial production by isolate 321.2 .

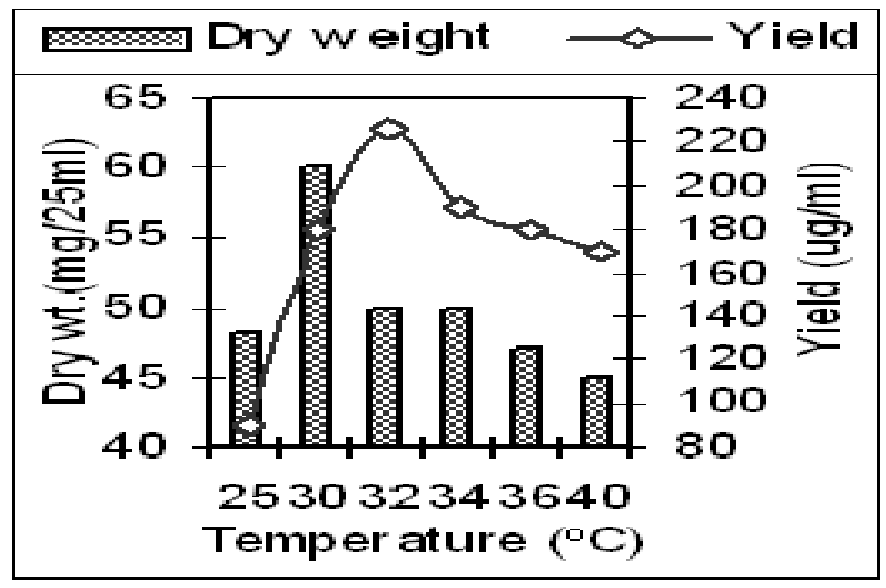

Figure 2. Effect of temperature for growth and antimicrobial production by isolate 321.2 .

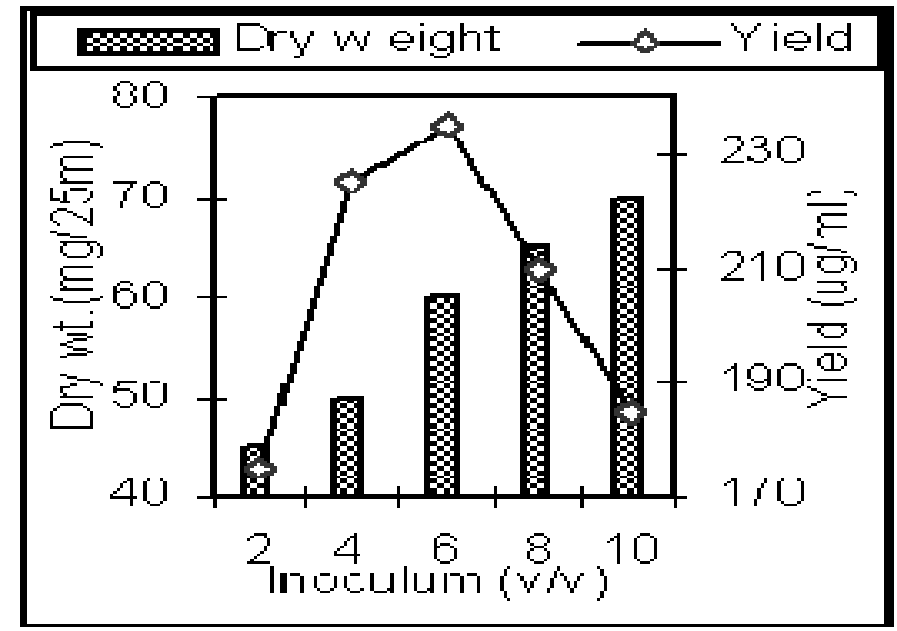

Figure 3. Effect of inoculum size for growth and antimicrobial production by isolate 321.2 .

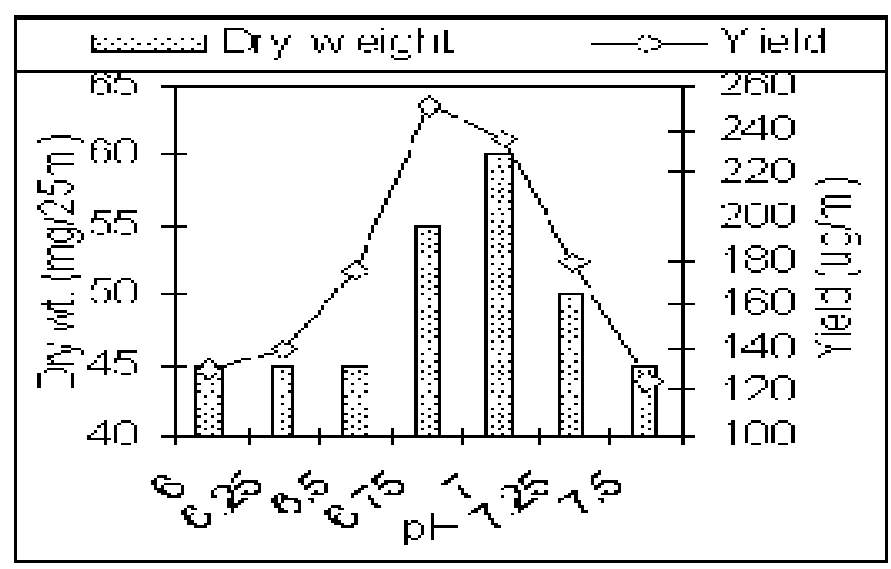

Figure 4. Effect of $\mathrm{pH}$ for growth and antimicrobial production by isolate 321.2 . 


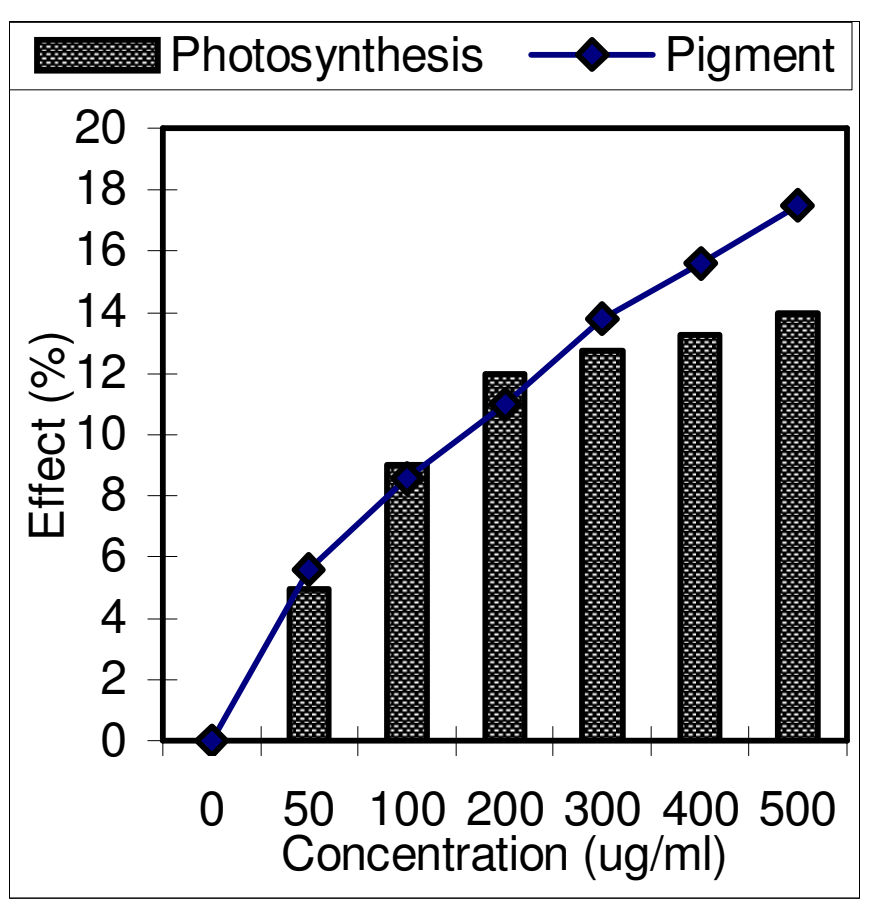

A
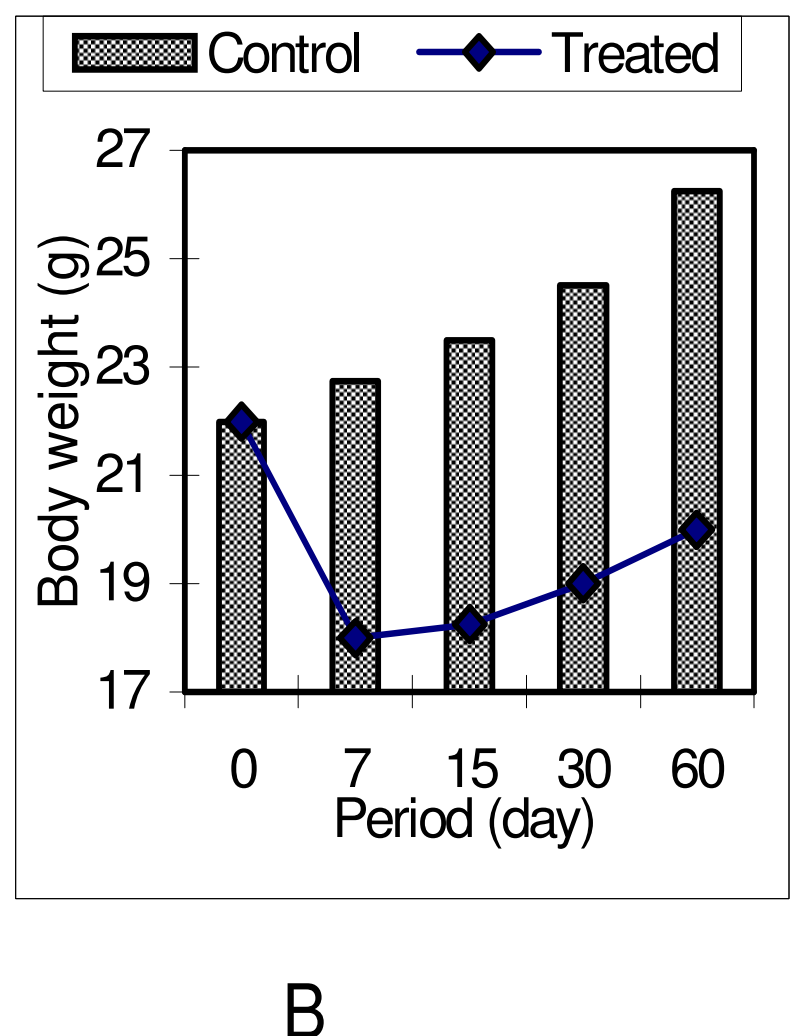

Figure 5. Toxicity test of the antimicrobial compound A) Phytotoxicity and B) Animal toxicity.

of cell permeability was studied with beet root. The experiment did not show much leaching of anthocyanine pigment even up to $6 \mathrm{~h}$ of treatment but the rate of leaching increased with increased concentration of active compound (Figure 5a). The compound did not influence much in photosynthesis rate and membrane permeability even in higher dose. Haque et al. (1996) noted insignificant inhibition in photosynthetic rate of the antimicrobial compound produced by $S$. antibioticus sr 15.4. In the animal toxicity experiment, there was no incidence of death of treated animals which was up to 60 days, while administered with active compound $(100 \mathrm{mg} / \mathrm{Kg})$. However, the loss of body weight was observed (Figure $5 b)$. But the results of animal toxicity tests may vary with the chemical nature of the compound and the route of administration to the experimental animal. The lowest observed adverse effect level (LOAEL) of DBP was 66 $\mathrm{mg} / \mathrm{kg} /$ day with diet in SD rats (Foster et al., 2000). Production of antimicrobials as secondary metabolite is controlled by the genetic make up of the organism. The fullest expression of this property is profoundly influenced by quality and quantity of medium, along with the environmental factors. The experimental data revealed that the isolate 321.2 under optimized physical parameters of selected medium could also be able to produce 250 $\mu \mathrm{g} / \mathrm{ml}$ of antimicrobial and exhibited very low toxic effects.

\section{REFERENCES}

Abou-Zeid AA, Nabih AB, Baghalf AO (1991). The formation of oxytetracycline in a date cote medium. Biores. Technol., 37: 179-184.

Agate AD, Bhat JV (1963). A method for the preferential isolation of actinomycetes. Antonie Van Leeuwenhok J. Microbiol. Serol., 29: 297-304.

Bhattacharyya BK, Sen SK (2002). Ester antibiotic accumulated by Streptomyces hygroscopicus. Microbiologica., 25: 477- 482.

Boeck LD, Fredrick PM, Claim GM (1985). A41030, a complex of noval glycopeptide antibiotics produced by a strain of Streptomyces virginiae. Taxonomy and fermentation studies. J. Antibiot., 38: 1-8.

Bressollier P, Letourneau F, Urdaci M, Verneuil B (1999). Purification and characterization of a keratinolytic serine proteinase from Streptomyces albidoflavus. Appl. Environ. Microbiol., 65: 2570-2576.

El-Gammal AA (1986). Characterization of an orange brown pigmented antiobiotic produced by Streptomyces viridiviolaceus. Egypt. J. Microbiol., 21: 37-42.

El-Nakeeb MA, Lechevalier HA (1963). Selective isolation of aerobic actinomycetes. Appl. Microbiol., 11: 75-77.

Ezaki M, Iwami M, Yamashita M, Hashimoto S, Komori T, Umehara K, Mine Y, Kosaka, M, Akoi H, Imanaka H (1985). Biphenomycins A \& $B$, novel peptide antibiotics: I. Taxonomy, fermentation, isolation and characterization. J. Antibiot., 38: 1453-1456.

Foster PM, Cattley RC, Mylchreest E (2000). Effects of di-n-butyl phthalate (DBP) on male reproductive development in rat: implications for human risk assessment. Food Chem. Toxicol., 38: S97-99.

Franco CMM, Borde UP, Vijayakumar EKS, Chatterjee S, Blumbach J, Ganguli BN (2000). Butalactin, a new butanolide antibiotic: Taxonomy, fermentation, isolation and biological activity. J. Antibiot., 44: $225-231$. 
Gause GF, Preobrazhenskaya TP, Kudrina ES, Blinow NO, Rjabova ID, Sveshnikova MA (1958). J. Classification Actinomycetes Fischer, Jena In: Haque SF, Sen SK, Pal SC (1995). Nutrient optimization for production of broad spectrum antibiotic by Streptomyces antibioticus

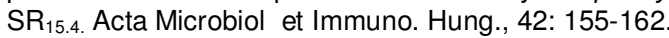

Haque SF, Sen SK, Pal SC (1996). Antimicrobial spectra and toxicity of antibiotics from Streptomyces antibioticus $\mathrm{Sr}_{15.4}$. Indian J. Microbiol., 36: 113-114.

Higashide E, Fugono T, Hatano K, Shibata M (1971). Studies on T2636 antibiotics. 1. Taxonomy of Streptomyces rochei var volubilis var nov. and production of the antibiotics and an esterase. J. Antibiot., 24: 112.

Hobbs G, Catherine M, Frazer CJ, Gardner JAC, Stephan GO (1989). Dispersed growth of Streptomyces in liquid culture. Appl. Microbiol. Biotechnol., 31: 272-277.

Kojiri K, Nakajima S, Suzuki H, Kondo H, Suda H (1992). A new macrocylic lactam antibiotic, BE-14106. I. Taxonomy, isolation, biological activity and structural elucidation. J. Antibiot., 45: 868-874.

Krainsky A (1941). Die Aktinomyceten und ihre Bedeutung in der Natur. Center. Bakteriol Parasitenk., 41: 649-688.

Lindenbein W (1952). Uber einige chemisch interessante Aktinomycetentamme und ihre Klassifizierung. Arch. Mikrobiol., 17: 361-383.

Mohamed MS, Rashad AE, Zaki MEA, Fatahala. SS (2005). Synthesis and antimicrobial screening of some fused heterocyclic pyrroles. Acta Pharm., 55: 237-249.

Mendo S, Faustino NA, Sarmento AG, Amando F, Moir AJG (2004). Purification and characterization of a new peptide antibiotic produced by a thermotolerant Bacillus licheniformis strain. Biotechnol. Lett., 26: 115-119.

Pepeljnjak S, Zorc B, Butula I (2005). Antimicrobial activity of some hydroxamic acid. Acta Pharm., 55: 401- 408.

Pridham TG, Gottlieb D (1948). The utilization of carbon compounds by some actinomycetes as an aid for species determination. $J$. Bacteriol., 56: 107-114.

Pridham TG, Anderson P, Foley C, Lindenfelser LA, Hesseltine CW, Benedict RG (1956-57). Selection of media for maintenance and taxonomic study of Streptomycetes. Antibiot. Ann, pp. 947-953.
Pridham TG, Lyons AJ Jr (1961). Streptomyces albus (Russi Doria) Waksman et Henrici: Taxonomic study of strain labeled Streptomyces albus. J. Bacteriol., 81: 431-441.

Roy RN, Sen SK (2002). Survey of antimicrobial streptomyceres from the soils of West Bengal: Characterization and identification of the potent broad spectrum antibiotic producing Streptomyces albidoflavus 321.2. Hind. Antibiot. Bull., 44:25-33.

Roy RN, Laskar S, Sen, SK (2006). Dibutyl phthalate, the bioactive compound produced by Streptomyces albidoflavus 321.2. Microbiol. Res., 161: 121-126.

Roy RN, Sen SK (2006). Thermal and pH stability of dibutyl phalate, an antimetabolite of proline from Streptomyces albodoflavus 321.2. J. Curr. Sci., 9: 471-474.

Sosa JM, Cventic Z (2005). Antimicrobial activity of N-Phthaloylamino acid hydroxamates. Acta Pharm., 55: 387-399.

Tsao PH, Leben C, Keitt GW (1960). An enrichment method for isolating actinomycetes that produce diffusible antifungal antibiotic. Pytopathol., 50: 88-89.

Ueki M, Kusumoto A, Hanafi M, Shibata K, Tanaka T, Taniguchi M (1997). UK 3A, a novel antifungal antibiotics from Streptomyces sp. 517-02. Fermentation, isolation, structural elucidation and biological properties. J. Antibiot., 50: 1052-1057.

Umezawa H (1982). Low-molecular-weight enzyme inhibitors of microbial origin. Ann. Rev. Microbiol., 36: 75-99.

Waksman SA (1957). Species concept among the actinomycetes with special reference to the genus Streptomyces. Bacteriol. Rev., 21: 129.

Wang SL, Yieh TC, Shih, IL (1999). Purification and characterization of a new antifungal compound produced by Pseudomonas aeruginosa K-187 in Shrimp and Crab shell power medium. Enz. Microbiol. Technol., 25: 439-446.

Watve MG, Tickoo R, Jog MM, Bhole BD (2001). How many antibiotics are produced by the genus Streptomyces? Arch. Microbiol., 176: 386390

Williams ST, Davis FL, Mayfield Cl, Khan MR (1971). Studies on the ecology of actinomycetes in soil. II. The $\mathrm{pH}$ requirement of Streptomyces from two soils. Soil Biol. Biochem., 3: 187-195. 